\title{
Clinical Profile of Urolithiasis Patients at Radiodiagnosis Department of a Tertiary Care Hospital
}

\author{
Abhang Apte ${ }^{1}$, Devidas Dahiphale ${ }^{1}$, Anjali Pawar Dahiphale ${ }^{2}$ \\ ${ }^{1}$ Associate Professor, Dept of Radiology, MGM Medical College, Aurangabad, Maharashtra, India. \\ ${ }^{2}$ Associate Professor, Dept of Radiology, Govt. Medical College, Aurangabad, Maharashtra, India
}

\begin{abstract}
:
Introduction: Urolithiasis is a multi-factorial disease involving genetic \& environmental factors. There has been an increased incidence of urolithiasis in recent times which has been associated with variations in its epidemiology like change in age, sex distribution of the disease and also changes in terms of type and location of the calculi. Present study describes clinical profile of urolithiasis patients visiting Radiodiagnosis department of a tertiary care hospital in Solapur district of Maharashtra state in India.

Methods: It is a descriptive observational study done at Dept of Radiodiagnosis \& Imaging at Shri Chhatrapati Shivaji Maharaj General Hospital in Solapur district of Maharashtra state in India. Study duration was Jan 2005 to Oct 2006. 120 patients who presented with symptoms \& signs of urolithiasis for diagnosis \& treatment in Dept of Surgery \& Medicine, including the referrals from other hospitals \& institutes \& referred to Dept of Radiodiagnosis \& Imaging of the institute for Computerised Tomography (CT) with provisional diagnosis of urolithiasis were enrolled. Detailed history \& physical examination was done. The description of clinical profile was done with respect to age, sex wise distribution \& location of the calculus.

Results: On evaluation, 100 patients were diagnosed as having urolithiasis. Median age was 35 years. Age of patients ranged from 2 years to 81 years. Maximum cases (35\%) were in age group of 31-40 years. Male to female ratio of patients was 2.4:1. Out of total 140 calculi in these patients, $54(36 \%)$ calculi were present in renal calyces (nephrolithiasis). Lower pole calyces were the most common site of nephrolithiasis (20\%). 96 $(64 \%)$ calculi were present in ureters. Most common site was distal $1 / 3^{\text {rd }}$ of ureters which was seen in 38 patients $(25.3 \%)$.
\end{abstract}

Conclusion: Urolithiasis patients were most common in age group of 31-40 years. Male to female ratio was 2.4:1. Ureteric calculi were more common than renal calculi.

Keywords: Nephrolithiasis, epidemiology of urinary calculi, Non contrast Spiral CT Scan.

\section{Introduction}

Urolithiasis is a multi-factorial disease involving genetic and environmental factors. Changes in socioeconomic status and diet habits may alter the epidemiology of urolithiasis in different areas of the world. These factors tend to happen at different times and to varying extents in different areas of the world. It has been reported that the incidence of urolithiasis has increased in line with the economic development and associated alterations in lifestyle and diet of the people and now it is among the common diseases posing a serious threat to health. The increased incidence of urolithiasis has been associated with variations in its epidemiology like change in age, sex distribution of the disease and also changes in terms of type and location of the calculi. [1, 2, 3] Present study describes clinical profile of urolithiasis patients visiting Radiodiagnosis department of a tertiary care hospital in Solapur district of Maharashtra state in India.

\section{Material And Methods}

It is a descriptive observational study. It was carried out in the Department of Radiodiagnosis \& Imaging at Shri Chhatrapati Shivaji Maharaj General Hospital, a tertiary care referral hospital in Solapur district of Maharashtra state in India. Study duration was from Jan 2005 to Oct 2006. 120 patients who presented with symptoms \& signs of urolithiasis for diagnosis \& treatment in Department of Surgery and Medicine, including the referrals from other hospitals \& institutes and referred to Department of Radiodiagnosis \& Imaging of the institute for Computerised Tomography (CT) with provisional diagnosis of urolithiasis were included in the study. Detailed history and physical examination was done. Informed consent was obtained from the subjects prior to enrolment in the study. The description of clinical profile was done with respect to age, sex wise distribution and location of the calculus.

\section{Results}

In hundred patients diagnosed as urolithiasis the mean age of presentation was 35 years. The age of patients ranged from 2 years to 81 years. 
The maximum cases (35\%) were in age group of 31-40 years.

Table 1: Age wise distribution of Urolithiasis.

\begin{tabular}{|c|c|c|}
\hline Age (years) & Number & Percentage \\
\hline \hline $1-10$ & 3 & $3 \%$ \\
\hline $11-20$ & 7 & $7 \%$ \\
\hline $21-30$ & 22 & $22 \%$ \\
\hline $31-40$ & 35 & $35 \%$ \\
\hline $41-50$ & 16 & $16 \%$ \\
\hline $51-60$ & 11 & $11 \%$ \\
\hline $61-70$ & 5 & $5 \%$ \\
\hline$>70$ & 1 & $1 \%$ \\
\hline Total & $\mathbf{1 0 0}$ & $\mathbf{1 0 0 . 0 0 \%}$ \\
\hline \hline
\end{tabular}

Table 2: Sex wise distribution of Urolithiasis.

\begin{tabular}{|c|c|c|}
\hline Male & Female & Total \\
\hline \hline 71 & 29 & $\mathbf{1 0 0}$ \\
\hline $71 \%$ & $29 \%$ & $\mathbf{1 0 0 \%}$ \\
\hline
\end{tabular}

Male to female ratio of patients with urolithiasis is $2.4: 1$

Table 3: Location of Calculus

\begin{tabular}{|c|c|c|}
\hline Nephrolithiasis & Number & Percentage \\
\hline \hline Upper pole & 6 & $4 \%$ \\
\hline Mid Pole & 18 & $20 \%$ \\
\hline Lower Pole & 30 & $\mathbf{3 6 \%}$ \\
\hline Total & $\mathbf{5 4}$ & Percentage \\
\hline Ureter & Number & $\mathbf{1 5 . 3 \%}$ \\
\hline Proximal 1/3 $^{\text {rd }}$ & $\mathbf{2 3}$ & $\mathbf{0 9 . 3 \%}$ \\
\hline Mid 1/3 $^{\text {rd }}$ & $\mathbf{1 4}$ & $\mathbf{2 5 . 3 \%}$ \\
\hline Distal 1/3 $^{\text {rd }}$ & $\mathbf{3 8}$ & $\mathbf{1 4 \%}$ \\
\hline Ureterovesical Junction & $\mathbf{2 1}$ & $\mathbf{6 4 \%}$ \\
\hline Total & $\mathbf{9 6}$ & \\
\hline
\end{tabular}

Out of 140 calculi, 54 (36\%) calculi were present in renal calyces (nephrolithiasis). Lower pole calyces were the most common site of nephrolithiasis (20\%). 96 (64\%) calculi were present in ureters. The most common site was distal $1 / 3^{\text {rd }}$ of ureters which was seen in 38 patients $(25.3 \%)$.

\section{Discussion}

The present study was done on 120 patients of clinically suspected urolithiasis during Jan 2005 to Oct 2006. The patients were studied by non-contrast spiral CT study in Department of Radiodiagnosis \& Imaging at Shri Chhatrapati Shivaji Maharaj General Hospital, Solapur, Maharashtra. In hundred patients diagnosed as urolithiasis, the median age of presentation was 35 years. The age of patients ranged from 2 years to 81 years. The maximum cases were in age group of 31-40 years (35\%). The observations of present study correspond with earlier studies. Keir Fowler et al [4] study on 123 subjects during 1997 to 2000, reported mean age of 42 years (age range: 14-82 years) in patients with renal calculi. A study by Ahmad F et al on 5371 consecutive patients over more than 3 years done at Saudi Arabia hospital which included patients from around 30 nationalities found that age of the patients ranged from 12 years to 65 years. Mean age was 36.6 years, with bimodal distribution and peaks at 30 and 40 years. Median age was 35 years with a standard deviation of 10.2 years. [5]

We observed that out of 100 patients with urolithiasis males $(71 \%)$ are predominantly involved than females (29\%). Male to female ratio of patients with urolithiasis is 2.4:1. A recent study by DY Hong et al [6] noted that Urolithiasis was more frequently seen in men than in women and male-to-female ratio was 2:1. They also found that peak incidence of renal colic occurred in the forties and early fifties age group while the median age was 45 years. Safarinejad MR [7] did a population based study on adult population in Iran on 8413 patients aged 14 years and above and reported that urinary calculi were more common in males than females with a male: female ratio of 1.15:1. Ahmad F et al study [5] reported a very high male to female ratio of 9.7:1. Study 
by Tanthanuch M [8] done on 10,344 patients of urolithiasis across South Thailand reported male to female ratio of 1.6: 1 whereas 41 - 50 years was the most common age group. Study by Qaader DS [9] in Iraq reported 38.3 years as mean age and 2.5:1 was the male to female ratio. Sasane and Singh [10] study published in 2015 described sixty one diagnosed urolithiasis patients from Pune region of Maharashtra in India. Mean age was 41 years. The age range was 21 years to 72 years. Maximum patients belonged to 31-40 years age group (27\%). Male to female ratio was $2.4: 1$.

In our study, out of total 140 calculi in the studied patients, $54(36 \%)$ calculi were present in renal calyces (nephrolithiasis). Lower pole calyces were the most common site of nephrolithiasis (20\%). 96 (64\%) calculi were present in ureters. Most common site was distal $1 / 3^{\text {rd }}$ of ureters which was seen in 38 patients (25.3\%). Tanthanuch M [8] observed that ureteric stones were more common than renal calculi in the study done on 10,344 patients of urolithiasis across South Thailand. However, study by Sasane and Singh [10] describing 145 calculi detected in 61 patients reported that Nephrolithiasis was seen in 93 cases (64\%), mid pole calyces were the most common location among these cases (40\%). Ureteric calculi were seen in $52(36 \%)$ cases. Study by Qaader DS [9] described the anatomical location of urinary calculi as $67.4 \%$ renal calculi, $12.5 \%$ ureteric calculi and $14.6 \%$ bladder calculi. Ahmad F et al [5] reported the anatomic location of total number of 1236 urinary calculi in 1029 patients of which $73.3 \%$ were renal calculi and $13 \%$ were ureteric calculi. There were $9.8 \%$ calculi located at vesico-ureteric junction, $2.3 \%$ calculi located at Pelvi-ureteric junction, $1.1 \%$ vesical calculi and $0.5 \%$ urethral calculi.

Limitations of the present study include hospital based observational study design with a relatively small and non representative sample, however considering limited literature available on the current topic from the region, it will add important data to the literature related to an important health issue from this geographical region.

\section{References}

[1]. Sudabeh Alatab, Gholamreza Pourmand, Mohammed El Fatih El Howairis, Noor Buchholz, Iraj Najafi, Mohammad Reza Pourmand, Rahil Mashhadi, Naghmeh Pourmand. National Profiles of Urinary Calculi: A Comparison Between Developing and Developed Worlds. IJKD 2016; 10:51-61.

[2]. Milosevic D, Batinic D, Turudic D, Batinic D, et al. (2014). Demographic characteristics and metabolic risk factors in Croatian children with urolithiasis. Eur. J. Pediatr. 173: 353-359.

[3]. H.C. Wang, C. Liu, H.Y. He and M.X. Wang. A case-control study on the risk factors of urinary calculus in Uyghur children in the Kashi region. Genetics and Molecular Research 2015; 14 (2): 5862-5869

[4]. Fowler KA, Locken JA, Duchesne JH, Williamson MR: US for detecting renal calculi with nonenhanced CT as a reference standard. Radiology 2002; 222:109-113.

[5]. Ahmad F, Nada MO, Farid AB, Haleem M A, Razack S. Epidemiology of urolithiasis with emphasis on ultrasound detection: A retrospective analysis of 5371 cases in Saudi Arabia. Saudi J Kidney Dis Transpl 2015;26:386-91

[6]. Hong DY, Kim JW, Lee KR, Park SO, Baek KJ. Epidemiologic and clinical characteristics of patients presenting with renal colic in Korea. Urol J 2015; 12: 2148-53.

[7]. Safarinejad MR. Adult urolithiasis in a population-based study in Iran: prevalence, incidence, and associated risk factors. Urol Res. 2007; 35(2):73-82.

[8]. Tanthanuch M, Apiwatgaroon A, Pripatnanont C. Urinary tract calculi in southern Thailand. J Med Assoc Thai. 2005 Jan;88(1):80-

[9]. Qaader DS, Yousif SY, Mahdi LK. Prevalence and etiology of urinary stones in hospitalized patients in Baghdad. East Mediterr Health J. 2006 Nov;12(6):853-61.

[10]. Amol Gorakhnath Sasane, Hariqbal Singh. Value of Unenhanced Spiral CT in Patients With Flank Pain and Clinical Suspicion of Urolithiasis. Indian Journal Of Applied Research 2015; 5 (2): 571 - 73 